\title{
A study of self-adhesive resin cements for bonding to silver-palladium- copper-gold alloy - Effect of including primer components in cement base
}

\author{
Koichi MURAGUCHI ${ }^{1}$, Hiroyuki MINAMI ${ }^{1}$, Yoshito MINESAKI ${ }^{1}$, Shiro SUZUKI ${ }^{2}$ and Takuo TANAKA ${ }^{3}$ \\ ${ }^{1}$ Fixed Prosthetic Clinic, Kagoshima University Medical and Dental Hospital, 8-35-1 Sakuragaoka, Kagoshima 890-8544, Japan \\ ${ }^{2}$ Department of Prosthodontics, School of Dentistry, University of Alabama at Birmingham, 1919 7th Ave., South, Birmingham, Alabama 35294-0007, \\ USA \\ ${ }^{3}$ Department of Fixed Prosthetic Dentistry, Advanced Therapeutic Course, Kagoshima University Graduate School of Medical and Dental Sciences, \\ 8-35-1 Sakuragaoka, Kagoshima 890-8544, Japan \\ Corresponding author, Koichi MURAGUCHI; E-mail: gutch@dent.kagoshima-u.ac.jp
}

\begin{abstract}
This study investigated the efficacies of adhesive resin cements (Clearfil SA Luting, Maxcem, G-CEM, RelyX Unicem Clicker, Vitremer Paste) for bonding to Ag-Pd-Cu-Au alloy not surface-pretreated with metal primer. For control, Panavia F 2.0 - developed for use with a proprietary metal primer, Alloy Primer - was tested with and without metal primer application. Pairs of alloy disks (10.0 and $8.0 \mathrm{~mm}$ in diameters, $3.0 \mathrm{~mm}$ thickness) were air-abraded with alumina and bonded with one of the cements. Shear bond strengths (SBSs) were measured before and after 50,000 times of thermocycling. Among Maxcem, RelyX Unicem Clicker and the control, there were no statistical differences in SBS before and after thermocycling. After thermocycling, Clearfil SA Luting exhibited the highest SBS among all the cements. Results showed that Clearfil SA Luting, Maxcem, and RelyX Unicem Clicker were efficacious for bonding to Ag-Pd-Cu-Au alloy after air abrasion surface treatment for the latter.
\end{abstract}

Keywords: Self-adhesive cement, Shear bond strength, Silver-palladium-copper-gold alloy

\section{INTRODUCTION}

In the cementation of prosthetic devices, the use of resin cements delivers myriad clinical benefits: (1) reduced incidence of secondary caries and subsequent pulp damage due to improved marginal sealing and low cement solubility ${ }^{1-3)}$; (2) effective prevention of root fractures when used for the cementation of cast postand-core build-ups ${ }^{4,5)}$; (3) improved fracture resistance, and hence extended longevity, for esthetic ceramic and composite resin prostheses when they are luted with adhesive resin cements ${ }^{6-8)}$. In light of these advantages, the clinical use of resin cements has risen steadily ${ }^{9}$.

For bonding with resin cements, proprietary surface treatments must be applied on the adhesive areas to achieve optimum bonding. Therefore, it has become a routine procedure to perform surface treatments on abutment teeth ${ }^{10-12)}$ and prostheses ${ }^{13-18)}$ prior to cementation with resin cements. However, the efficacy of surface treatments is dependent upon the skills and experience of operators in the handling of specific equipment and in the execution of sensitive manipulations ${ }^{19,20)}$. To eliminate such dependency and hence uncertainty in achieving optimal restorative treatment results, there emerged a natural progression toward the development of resin cements which could provide sufficient bond strength but with a simple surface treatment.

Currently, resin cements can be classified into two groups according to their bonding procedures: luting resin cements versus adhesive resin cements. Luting resin cements require a priming process or surface pretreatment (such as tin-plating) of the bonding substrates. Adhesive resin cements, on the other hand, do away with the priming process because they contain adhesive components in the cement base, such that direct bonding with the substrates is provided by these adhesive monomers. Lately, adhesive resin cements that appeared on the market do not specify the use of primers for the cementation of metal restorations in their operation manuals. These adhesive resin cements were developed by different manufacturers and have been assessed in numerous studies.

The purpose of this study was to investigate the potential of five self-adhesive resin cements containing primer components for the cementation of silverpalladium-copper-gold (Ag-Pd-Cu-Au) alloy restorations. The Ag-Pd-Cu-Au alloy was not surface-pretreated with metal primer application, and thermocycling was used to simulate the aging of dental restorations. Before and after thermocycling, the shear bond strengths (SBSs) of these five adhesive resin cements to the alloy were measured and then compared with those obtained from an adhesive resin cement that required metal primer surface pretreatment.

\section{MATERIALS AND METHODS}

\section{Materials}

Table 1 presents the materials used in this study and their compositions. An Ag-Pd-Cu-Au alloy (Castwell M.C. 12, GC Corp., Tokyo, Japan) was selected for the adherend. Five adhesive resin cements examined in this study were Clearfil SA Luting (SA; Kuraray Medical Inc., Tokyo, Japan), Maxcem (MA; Kerr Corp., Orange CA, USA), G-CEM (GC; GC Corp.), RelyX Unicem Clicker 
(UC; 3M ESPE, St. Paul, MN, USA), and Vitremer Paste (VT; 3M ESPE). According to their manufacturers, these adhesive resin cements were not developed for use with any proprietary metal primer.

Panavia F 2.0 (PV; Kuraray Medical), which required the application of proprietary metal primer Alloy Primer (AP; Kuraray Medical Inc.), was used as a control. Its results with and without metal primer application were then compared with those of the above adhesive resin cements without metal primer surface treatment.

Table 1 Materials used in this study

\begin{tabular}{|c|c|c|c|c|c|}
\hline Material & Brand Name & Content & Manufacturer & Batch number & Code \\
\hline \multicolumn{6}{|c|}{$\begin{array}{l}\text { Adhesive } \\
\text { resin Cement }\end{array}$} \\
\hline & $\begin{array}{l}\text { Clearfil SA } \\
\text { Luting }\end{array}$ & $\begin{array}{l}\text { Paste A: Bis-GMA, TEGDMA, MDP, other } \\
\text { methacrylate monomers, silanated barium } \\
\text { glass filler, silanated colloidal silica, } \\
\text { dl-camphorquinone, benzoyl peroxide, others } \\
\text { Paste B: Bis-GMA, other methacrylate } \\
\text { monomers, silanated barium glass filler, } \\
\text { silanated colloidal silica, surface treated } \\
\text { sodium fluoride, accelerators, pigments, } \\
\text { others }\end{array}$ & $\begin{array}{l}\text { Kuraray } \\
\text { Medical Inc., } \\
\text { Tokyo, Japan }\end{array}$ & 0057AA & SA \\
\hline & Maxcem & $\begin{array}{l}\text { Base: UDMA, dl-camphorquinone, } \\
\text { fluoroaluminosilicate glass, others } \\
\text { Catalyst: Bis-GMA, TEGDMA, GPDM, } \\
\text { barium aluminoborosilicate glass, others }\end{array}$ & $\begin{array}{l}\text { Kerr Corp., } \\
\text { Orange, CA, } \\
\text { USA }\end{array}$ & 2976773 & MA \\
\hline & G-CEM & $\begin{array}{l}\text { Powder: fluoroaluminosilicate glass, } \\
\text { initiators, pigments, others } \\
\text { Liquid: methacrylate ester, 4-MET, } \\
\text { phosphate ester monomer, purified water, } \\
\text { silica nano filler, initiators, others }\end{array}$ & $\begin{array}{l}\text { GC Corp., } \\
\text { Tokyo, Japan }\end{array}$ & 0803261 & $\mathrm{GC}$ \\
\hline & $\begin{array}{l}\text { RelyX Unicem } \\
\text { Clicker }\end{array}$ & $\begin{array}{l}\text { Unknown in detail: glass powder, } \\
\text { methacrylated phosphoric acid esters, } \\
\text { TEGDMA, silane treated silica, sodium } \\
\text { persulfate }\end{array}$ & $\begin{array}{l}3 \mathrm{M} \text { ESPE, } \\
\text { St Paul, MN, } \\
\text { USA }\end{array}$ & 274863 & $\mathrm{UC}$ \\
\hline & $\begin{array}{l}\text { Vitremer } \\
\text { Paste }\end{array}$ & $\begin{array}{l}\text { Paste A: silanated glass, HEMA, purified } \\
\text { water, others } \\
\text { Paste B: polycarboxylic acid, zirconia-silica, } \\
\text { HEMA, purified water, Bis-GMA, sulphates, } \\
\text { others }\end{array}$ & $\begin{array}{l}3 \mathrm{M} \text { ESPE, } \\
\text { St Paul, MN, } \\
\text { USA }\end{array}$ & NY8MG & VT \\
\hline & Panavia F 2.0 & $\begin{array}{l}\text { Paste A: MDP, methacrylate monomer, } \\
\text { filler, photo initiator, chemical initiator } \\
\text { Paste B: methacrylate monomer, photo } \\
\text { initiator, chemical initiator }\end{array}$ & $\begin{array}{l}\text { Kuraray } \\
\text { Medical Inc., } \\
\text { Tokyo, Japan }\end{array}$ & $\begin{array}{l}\text { A: } 00417 \mathrm{~A} \\
\text { B: } 00216 \mathrm{~A}\end{array}$ & PV \\
\hline \multicolumn{6}{|c|}{ Metal primer } \\
\hline & Alloy Primer & VBATDT, MDP, acetone & $\begin{array}{l}\text { Kuraray } \\
\text { Medical Inc., } \\
\text { Tokyo, Japan }\end{array}$ & 00350A & $\mathrm{AP}$ \\
\hline \multicolumn{6}{|l|}{$\begin{array}{l}\text { Adherend } \\
\text { material }\end{array}$} \\
\hline & $\begin{array}{l}\text { Castwell } \\
\text { M.C.12 }\end{array}$ & $\begin{array}{l}\text { silver }(46 \%) \text {, palladium }(20 \%) \text {, copper }(20 \%) \text {, } \\
\text { gold }(12 \%)\end{array}$ & $\begin{array}{l}\text { GC Corp., } \\
\text { Tokyo, Japan }\end{array}$ & & \\
\hline
\end{tabular}

Bis-GMA : Bis-phenol A diglycidylmethacrylate

TEGDMA : Triethyleneglycol dimethacrylate

MDP : 10-Methacryloyloxydecyl dihydrogen phosphate

UDMA : Urethane Dimethacrylate

GPDM : Glycerophosphoric acid dimethacrylate

4-MET : 4-methacryloxyethyl trimellitic acid

HEMA : 2-hydroxyethylmethacrylate

VBATDT : 6-(4-vinylbenzyl-n-propyl) amino-1, 5-triazine-2, 4-dithiol 


\section{Bonding procedure}

A total of 98 sets of disks $(10.0 \mathrm{~mm}$ and $8.0 \mathrm{~mm}$ in diameters, $3.0 \mathrm{~mm}$ thickness) were cast using $\mathrm{Ag}-\mathrm{Pd}-\mathrm{Cu}-\mathrm{Au}$ alloy according to the manufacturer's instruction. Bonding surfaces of the disks were polished with \#600 silicon carbide papers, followed by airborneparticle abrasion using $50 \mu \mathrm{m}$ alumina particles with a $0.5 \mathrm{MPa}$ pressure for 10 seconds. Distance between the nozzle and the alloy surface was set to $5.0 \mathrm{~mm}$.

To demarcate the bonding area, the $10.0 \mathrm{~mm}$ diameter disks were covered with a masking tape with a circular hole $5.0 \mathrm{~mm}$ in diameter. The $8.0 \mathrm{~mm}$ diameter disks were then cemented onto the demarcated bonding area with one of the five adhesive resin cements without metal primer application. All bonding procedures were carried out according to the manufacturers' instructions, and there were 14 specimens in each group.

For the two control groups, Panavia F 2.0 was applied on the airborne-particle abraded alloy surface with (group APV) and without metal primer application (group AP). Similarly, there were 14 specimens in each control group.

\section{Shear bond strength measurement}

At 30 minutes after the bonded specimens were prepared, they were immersed in $37^{\circ} \mathrm{C}$ distilled water and stored for 24 hours. This state was defined as 0 cycles of thermocycling, and shear bond strengths were measured using half of the specimens in each group $(n=7)$. The rest of the specimens in each group $(n=7)$ were subjected to 50,000 times of thermocycling (one-minute dwell time each in $4^{\circ} \mathrm{C}$ and $60^{\circ} \mathrm{C}$ ), and then shear bond strengths were measured (Fig. 1).

Shear bond strength testing was performed using a universal testing machine (AGS-5kNG, Shimadzu Corp.,

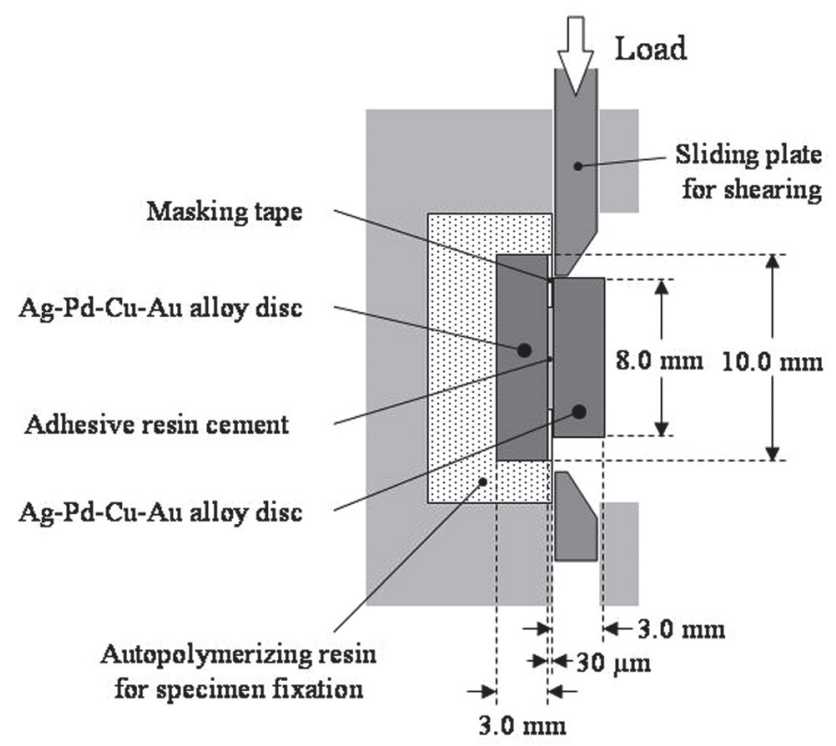

Fig. 1 Cross-sectional illustration of shear bond strength test.
Kyoto, Japan) at a $1.0 \mathrm{~mm} / \mathrm{min}$ crosshead speed. The data were statistically analyzed with two-way ANOVA, and multiple comparisons were performed using Tukey's test at $95 \%$ of confidence level.

\section{Failure mode analysis}

After shear bond strength testing, the fractured surfaces of all specimens with and without thermocycling were analyzed using an optical microscope (SMZ-10, Nikon Corp., Tokyo, Japan) under $\times 20$ magnification. Failure modes were classified as adhesive failure (A), cohesive failure (C), or mixed failure (M).

Failure mode classification was carried out by examining the fracture surfaces of both $10 \mathrm{~mm}$ diameter and $8 \mathrm{~mm}$ diameter disks. Adhesive failure was thus determined when debonding occurred at the interface between cement and either disk surface. Cohesive failure was when the fracture occurred within the cement layer. Mixed failure was when the specimen exhibited a combination of adhesive and cohesive failures.

\section{RESULTS}

Shear bond strength

Figure 2 presents the SBS results of respective adhesive resin cements to the $\mathrm{Ag}-\mathrm{Pd}-\mathrm{Cu}-\mathrm{Au}$ alloy and their statistical analyses. Two-way ANOVA showed that there were significant differences in SBS among the cements $(p<0.0001)$ as well as between the thermocycled and non-thermocycled groups $(p<0.0001)$. In addition, a statistically significant interaction $(p<0.0001)$ was found

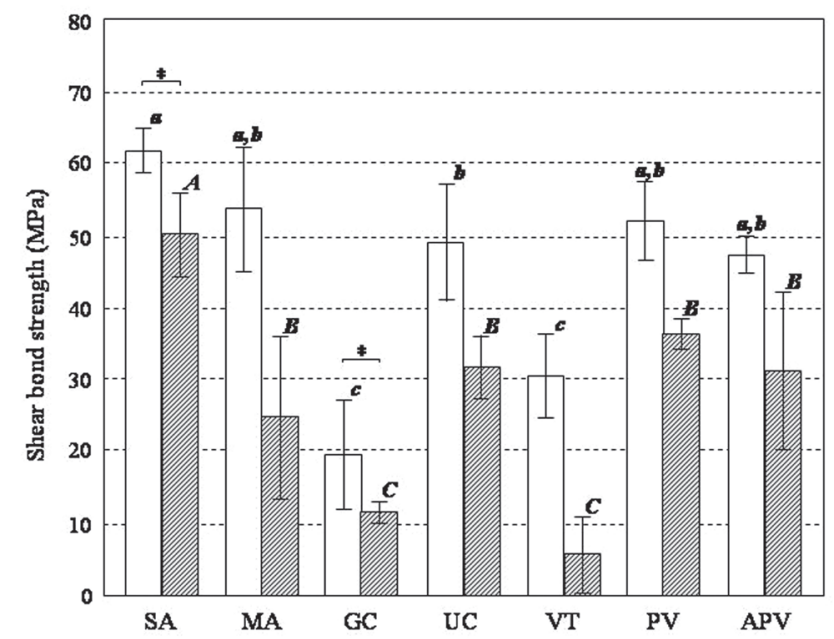

Fig. 2 Shear bond strengths of adhesive resin cements to $\mathrm{Ag}-\mathrm{Pd}-\mathrm{Cu}-\mathrm{Au}$ alloy.

Without thermocycling

After 50,000 thermocycles

Bars connected with brackets marked with * were not significantly different $(p>0.05)$.

Values with the same superscript letters were not significantly different $(p>0.05)$ within the same thermocycling state, i.e., before or after 50,000 times of thermocycling. 
Table 2 Failure modes of each group

\begin{tabular}{|c|c|c|c|c|c|c|}
\hline & \multicolumn{3}{|c|}{ Before thermocycling } & \multicolumn{3}{|c|}{ After 50,000 thermocycles } \\
\hline & $\begin{array}{c}\text { Adhesive } \\
\text { failure }\end{array}$ & $\begin{array}{l}\text { Cohesive } \\
\text { failure }\end{array}$ & $\begin{array}{l}\text { Mixed } \\
\text { failure }\end{array}$ & $\begin{array}{c}\text { Adhesive } \\
\text { failure }\end{array}$ & $\begin{array}{c}\text { Cohesive } \\
\text { failure }\end{array}$ & $\begin{array}{l}\text { Mixed } \\
\text { failure }\end{array}$ \\
\hline SA & 4 & 0 & 3 & 4 & 0 & 3 \\
\hline MA & 1 & 0 & 6 & 5 & 0 & 2 \\
\hline GC & 2 & 0 & 5 & 7 & 0 & 0 \\
\hline $\mathrm{UC}$ & 2 & 0 & 5 & 3 & 0 & 4 \\
\hline VT & 1 & 0 & 6 & 7 & 0 & 0 \\
\hline PV & 4 & 0 & 3 & 4 & 0 & 3 \\
\hline APV & 4 & 0 & 3 & 4 & 0 & 3 \\
\hline
\end{tabular}

between the factors of cement and the thermocycling regime.

Before thermocycling, the SBSs of SA, MA, and UC were not significantly different from those of control groups PV and APV $(p<0.0001)$. As for the SBSs of GC and VT, they were significantly lower than the control groups PV and APV $(p<0.0001)$.

After thermocycling, all other groups - except SA and GC- exhibited significantly lower SBS values $(p<0.0001)$. Among all the cements, SA exhibited the highest SBS at $50.5 \pm 5.8 \mathrm{MPa}(p<0.0001)$. The SBSs of MA and UC were not significantly different from those of control groups PV and APV (MA: $p=0.9964$, UC: $p>0.999$ ), but the SBSs of GC and VT were significantly lower than the control groups $(p<0.0001)$.

Within each adhesive resin cement group, SA and GC showed no significant decrease in SBS after thermocycling (SA: $p=0.6902$, GC: $p=0.9716)$. Between the control groups PV and APV, there were no significant differences between their SBS values before and after thermocycling.

\section{Failure modes}

Table 2 presents the failure mode results of all the specimens in this study. After shear bond strength testing, all the specimens exhibited either adhesive or mixed failure - be it with or without thermocycling. After thermocycling, MA, GC, UC, and VT showed an increase in adhesive failure incidences whereas SA, PV, and APV showed no such increase.

\section{DISCUSSION}

Except for PV, the adhesive resin cements evaluated in the current study contained adhesion-promoting monomers for dental metal alloys (Table 1), hence eliminating the need for metal primer application. These adhesive resin cements were introduced to simplify the bonding procedure as well as eliminate unexpected, undesirable clinical incidents. The priming process requires auxiliary materials and additional manipulations, such that patients have heightened risks of accidental ingestion of the primer or aspiration of organic solvents contained in the primer.
Thermocycling was employed in the current study to evaluate bonding durability, chiefly because the mechanical properties and adhesive strengths of resin cements are affected by hydrolysis and thermal expansion/contraction which occurred during thermocycling ${ }^{21)}$. SA exhibited superior bonding durability, with no statistically significant difference in SBS before and after thermocycling and yielding the highest SBS among all the cements after thermocycling. Two reasons probably accounted for this result: inclusion of adhesive monomer MDP and an improved polymerization initiation system ${ }^{22)}$.

It has been reported that the MDP monomer demonstrated excellent bonding to non-precious alloys ${ }^{23-25)}$. Ag-Pd-Cu-Au alloy employed in this study contained $46 \% \mathrm{Ag}, 20 \% \mathrm{Pd}, 20 \% \mathrm{Cu}$, and $12 \% \mathrm{Au}$ (Table 1). It was highly probable that the MDP monomer chemically reacted with $\mathrm{Cu}$ and hence resulted in the superior bonding durability of SA against thermocycling. Interestingly, PV also contained the MDP monomer but exhibited inferior bonding durability when compared to SA. This disparity might stem from a difference in their polymerization initiation systems. Therefore, in conjunction with the MDP monomer, the improved polymerization system of SA resulted in superior mechanical properties and consequently resulted in improved bonding durability.

MA and UC contained phosphoric functional monomers which render the same effect as $\mathrm{MDP}^{26-29)}$. As a result, there were no significant differences in SBS between MA and UC both before and after thermocycling. After thermocycling, the adhesive failure rate of MA increased but not so for UC. However, both MA and UC exhibited significantly lower SBS values after thermocycling. Based on the SBS and failure mode results, the SBS of MA became lower probably because of reduced adhesive strength caused by the thermocycling process; similarly, deterioration in the mechanical properties of UC caused by thermocycling resulted in its significantly lower SBS.

GC contained 4-MET as a functional monomer which ionically interacts with enamel and dentin ${ }^{30-32)}$, whereas HEMA contained in VT chemically interacts with dentin ${ }^{33,34)}$. As HEMA is a hydrophilic monomer, it 
might induce hydrolysis. Compared to other resin cements, GC and VT exhibited inferior SBS both before and after thermocycling. After thermocycling, all the specimens of GC and VT exhibited adhesive failure. It is therefore reasonable to conclude that 4-MET and HEMA offered unsatisfactory bonding to $\mathrm{Ag}-\mathrm{Pd}-\mathrm{Cu}-\mathrm{Au}$ alloy.

In the present study, the precious metal content of the tested alloy was quite high. Therefore, the availability of sulfur-containing monomers such as VBATDT and MTU-6 (6-methacryloyloxyhexyl-2thiouracil-5carboxylate) that promote adhesion to precious alloys ${ }^{35-38)}$ could have improved the bond strength and bonding durability of cements. However, sulfur-containing monomers are not suitable for resin cements that polymerize by BPO-amine redox system as they disturb the smooth progress of the radical polymerization initiated by BPO-amine reaction, consequently causing the resin cements to have weakened mechanical properties $^{39-41)}$. The Alloy Primer of Panavia F 2.0 contained VBATDT, but there were no statistically significant differences in SBS between APV and PV both before and after thermocycling. It was reasonable to suggest that when the resin cement came into contact with the VBATDT monomer on the primed alloy surface, the sulfur-containing VBATDT monomer inhibited the polymerization reaction, thus causing APV to have weakened mechanical properties and hence its SBS was adversely affected.

For bonding systems that require preliminary application of adhesive primers, it is not necessary to include adhesive monomers in their cement base formulations. From the perspective of long-term stability of cement paste, these systems are advantageous because no adhesive monomers are present in the cement base to interfere with the function of the polymerization initiator. However, herein emerges a new possibility of adhesive monomers in the primer interfering unfavorably with the polymerization initiators in the cement, thereby inhibiting the polymerization reaction. In such cases, it is recommended to add a polymerization accelerator to the primer or apply an intermediate resin layer on the primed surface.

In the present study, none of the specimens exhibited cohesive failure. A few explanations are proposed for this phenomenon. First, mechanical strength at the alloy-cement interface was inferior to the cohesive strength of resin cement itself; alternatively, there were pockets of area within the interface which possessed inferior bonding capacity compared to the cohesive strength of resin cement. For most resin cements in this study -except SA, PV, and APV, their incidences of adhesive failure increased after thermocycling. But for SA, PV, and APV which contained MDP as an adhesive monomer, their failure distribution modes before and after thermocycling remained the same. In the case of SA, this could be attributed to its superior bonding durability which then shielded its SBS from severe deterioration.

It was reported in numerous studies that cohesive failure was the predominant failure mode for adhesive resin cements bonded to oxidized surfaces of $\mathrm{Ag}-\mathrm{Pd}-\mathrm{Cu}-\mathrm{Au}$ alloys before thermocycling ${ }^{42}$. When $\mathrm{Ag}-\mathrm{Pd}-\mathrm{Cu}-\mathrm{Au}$ alloy restorations were cemented with adhesive resin cements, deterioration occurred at the bonding interface rather than within the cement material itself ${ }^{43,44)}$. Therefore in this study, although SA did not show a significant decrease in SBS after thermocycling, it was probable that the cohesive strength of the cement adjacent to oxidized alloy surface might be greater than the bond strength of SA. This suggestion could find its support and endorsement in clinical studies ${ }^{45,46)}$ which reported that the incidences of adhesive failure at the alloy-cement interface increased with prolonged service period of $\mathrm{Ag}-\mathrm{Pd}-\mathrm{Cu}-\mathrm{Au}$ alloy restorations cemented with adhesive resin cements.

To compensate for future decrease in bond strength for $\mathrm{Ag}-\mathrm{Pd}-\mathrm{Cu}-\mathrm{Au}$ alloy restorations cemented with adhesive resin cements, the cement adjacent to the alloy-cement interface must have sufficiently high cohesive strength immediately after cementation. This meant that for all the adhesive resin cements tested in this study, their applicability for bonding restorations that require long-term bonding durability (such as fixed partial dentures) would need further investigation, since their cohesive strengths were not investigated in this study. Nonetheless, SA demonstrated durable bonding to Ag-Pd-Cu-Au alloy after 50,000 times of thermocycling. Thus, SA seemed to be applicable for conventional restorations including inlays/onlays or crowns of which their retention is enhanced by mechanical interlocking.

\section{CONCLUSIONS}

Within the limitations of the current study, the following conclusions were drawn based on the obtained results:

1. Between the primed and non-primed control groups of Panavia F 2.0, there were no statistically significant differences in SBS before and after thermocycling.

2. Before thermocycling, there were no statistically significant differences in SBS among Clearfil SA Luting, Maxcem, RelyX Unicem Clicker, and the Panavia F 2.0 control groups.

3. After thermocycling, there were no statistically significant differences in SBS among Maxcem, RelyX Unicem Clicker, and the Panavia F 2.0 control groups.

4. Among all the adhesive resin cements, Clearfil SA Luting exhibited the highest SBS $(50.5 \pm 5.8 \mathrm{MPa})$ to the airborne particle-abraded alloy after thermocycling.

5. With or without thermocycling, all the cements tested exhibited either adhesive or mixed failure after shear bond strength testing. For Clearfil SA Luting, Panavia F 2.0, and Panavia F 2.0 with Alloy Primer, their failure distribution modes did not change after thermocycling.

6. G-Cem and Vitremer Paste could not achieve sufficient bonding durability with $\mathrm{Ag}-\mathrm{Pd}-\mathrm{Cu}-\mathrm{Au}$ alloy. 


\section{REFERENCES}

1) de la Macorra JC, Pradíes G. Conventional and adhesive luting cements. Clin Oral Invest 2002; 6: 198-204.

2) Johnson GH, Hazelton LR, Bales DJ, Lepe X. The effect of a resin-based sealer on crown retention for three types of cement. J Prosthet Dent 2004; 91: 428-435.

3) Schenke F, Hiller KA, Schmalz G, Federlin M. Marginal integrity of partial ceramic crowns within dentin with different luting techniques and materials. Oper Dent 2008; 33: 516-525.

4) Toman M, Toksavul S, Sarikanat M, Nergiz I, Schmage P. Fracture resistance of endodontically treated teeth: effect of tooth coloured post material and surface conditioning. Eur J Prosthodont Restor Dent 2010; 18: 23-30.

5) Soares CJ, Raposo LH, Soares PV, Santos-Filho PC, Menezes MS, Soares PB, Magalhães D. Effect of different cements on the biomechanical behavior of teeth restored with cast doweland-cores -in vitro and FEA analysis. J Prosthodont 2010; 19: 130-137.

6) Krämer N, Lohbauer U, Frankenberger R. Adhesive luting of indirect restorations. Am J Dent 2000; 13: 60D-76D.

7) Federlin M, Schmidt S, Hiller KA, Thonemann B, Schmalz G. Partial ceramic crowns: influence of preparation design and luting material on internal adaptation. Oper Dent 2004; 29: 560-570.

8) Santos GC Jr, Santos MJ, Rizkalla AS. Adhesive cementation of etchable ceramic esthetic restorations. J Can Dent Assoc 2009; 75: 379-384.

9) Capa N, Ozkurt Z, Canpolat C, Kazazoglu E. Shear bond strength of luting agents to fixed prosthodontic restorative core materials. Aust Dent J 2009; 54: 334-340.

10) Kajihara H, Suzuki S, Minesaki Y, Kurashige H, Tanaka T. Effect of filler loading on resin cement bonding to silanized buildup composites. Am J Dent 2005; 18: 109-112.

11) D'Arcangelo C, De Angelis F, D'Amario M, Zazzeroni S, Ciampoli C, Caputi S. The influence of luting systems on the microtensile bond strength of dentin to indirect resin-based composite and ceramic restorations. Oper Dent 2009; 34: 328-336.

12) Taira $Y$, Soeno K. The effect of a peroxidase primer on bond strength of three luting systems to dentin. Eur J Oral Sci 2009; 117: 306-311.

13) Wolfart M, Lehmann F, Wolfart S, Kern M. Durability of the resin bond strength to zirconia ceramic after using different surface conditioning methods. Dent Mater 2007; 23: 45-50.

14) Boscato N, Della Bona A, Del Bel Cury AA. Influence of ceramic pre-treatments on tensile bond strength and mode of failure of resin bonded to ceramics. Am J Dent 2007; 20: 103-108.

15) D'Arcangelo C, Vanini L. Effect of three surface treatments on the adhesive properties of indirect composite restorations. J Adhes Dent 2007; 9: 319-326.

16) Furuchi M, Oshima A, Ishikawa Y, Koizumi H, Tanoue N, Matsumura H. Effect of metal priming agents on bond strength of resin-modified glass ionomers joined to gold alloy. Dent Mater J 2007; 26: 728-732.

17) Hori S, Minami H, Minesaki Y, Matsumura H, Tanaka T. Effect of hydrofluoric acid etching on shear bond strength of an indirect resin composite to an adhesive cement. Dent Mater J 2008; 27: 515-522.

18) Taira Y, Kamada K, Atsuta M. Effects of primers containing thiouracil and phosphate monomers on bonding of resin to Ag-Pd-Au alloy. Dent Mater J 2008; 27: 69-74.

19) Stoknorm R, Isidor F, Ravnholt G. Tensile bond strength of resin luting cement to a porcelain-fusing noble alloy. Int $\mathrm{J}$ Prosthodont 1996; 9: 323-330.

20) Moulin P, Degrange M, Picard B. Influence of surface treatment on adherence energy of alloys used in bonded prosthetics. J Oral Rehabil 1999; 26: 413-421.

21) Matsumura H, Tanaka T, Atsuta M. Bonding of silverpalladium-copper-gold alloy with thiol derivative primers and tri-n-butylborane initiated luting agents. J Oral Rehabil 1997; 24: 291-296.

22) Nakamura T, Wakabayashi K, Kinuta S, Nishida H, Miyamae M, Yatani H. Mechanical properties of new self-adhesive resin-based cement. J Prosthodont Res 2010; 54: 59-64.

23) Matsumura H, Tanaka T, Taira Y, Atsuta M. Bonding of a cobalt-chromium alloy with acidic primers and tri-nbutylborane-initiated luting agents. J Prosthet Dent 1996; 76: 194-199.

24) Almilhatti HJ, Giampaolo ET, Vergani CE, Machado AL, Pavarina AC, Betiol EA. Adhesive bonding of resin composite to various $\mathrm{Ni}-\mathrm{Cr}$ alloy surfaces using different metal conditioners and a surface modification system. J Prosthodont 2009; 18: 663-669.

25) Masuno T, Koizumi H, Ishikawa Y, Nakayama D, Yoneyama T, Matsumura H. Effect of acidic monomers on bonding to SUS XM27 stainless steel, iron, and chromium with a tri-nbutylborane-initiated acrylic resin. J Adhes Dent 2010 in press.

26) Chai J, Chu FC, Chow TW, Liang BM. Shear bond strength between nickel-chromium and human dentine using a dual-cure, self-adhesive universal resin luting agent. Eur J Prosthodont Restor Dent 2008; 16: 85-88.

27) Elsayed ME, El-Mowafy O, Fenton A. Retention of overdenture posts cemented with self-adhesive resin cements. Int J Prosthodont 2009; 22: 287-289.

28) Capa N, Ozkurt Z, Canpolat C, Kazazoglu E. Shear bond strength of luting agents to fixed prosthodontic restorative core materials. Aust Dent J 2009; 54: 334-340.

29) Zhang C, Degrange M. Shear bond strengths of self-adhesive luting resins fixing dentine to different restorative materials. J Biomater Sci Polym Ed 2010; 21: 593-608.

30) Hotta K, Mogi M, Miura F, Nakabayashi N. Effect of 4-MET on bond strength and penetration of monomers into enamel. Dent Mater 1992; 8: 173-175.

31) Nagakane K, Yoshida Y, Hirata I, Fukuda R, Nakayama Y, Shirai K, Ogawa T, Suzuki K, Van Meerbeek B, Okazaki M. Analysis of chemical interaction of 4-MET with hydroxyapatite using XPS. Dent Mater J 2006; 25: 645-649.

32) Viotti RG, Kasaz A, Pena CE, Alexandre RS, Arrais CA, Reis AF. Microtensile bond strength of new self-adhesive luting agents and conventional multistep systems. J Prosthet Dent 2009; 102: 306-312.

33) Nishiyama N, Suzuki K, Nagatsuka A, Yokota I, Nemoto K. Dissociation states of collagen functional groups and their effects on the priming efficacy of HEMA bonded to collagen. J Dent Res 2003; 82: 257-261.

34) Carvalho RM, Mendonça JS, Santiago SL, Silveira RR, Garcia FC, Tay FR, Pashley DH. Effects of HEMA/solvent combinations on bond strength to dentin. J Dent Res 2003; 82: 597-601.

35) Matsumura H, Kamada K, Tanoue N, Atsuta M. Effect of thione primers on bonding of noble metal alloys with an adhesive resin. J Dent 2000; 28: 287-293.

36) Suzuki M, Yamamoto M, Fujishima A, Miyazaki T, Hisamitsu H, Kojima K, Kadoma Y. Raman and IR studies on adsorption behavior of adhesive monomers in a metal primer for $\mathrm{Au}, \mathrm{Ag}$, $\mathrm{Cu}$, and Cr surfaces. J Biomed Mater Res 2002; 62: 37-45.

37) Parsa RZ, Goldstein GR, Barrack GM, LeGeros RZ. An in vitro comparison of tensile bond strengths of noble and base metal alloys to enamel. J Prosthet Dent 2003; 90: 175-183.

38) Okuya N, Minami H, Kurashige H, Murahara S, Suzuki S, Tanaka T. Effects of metal primers on bonding of adhesive resin cement to noble alloys for porcelain fusing. Dent Mater J 2010; 29: 177-187.

39) Atsuta M, Matsumura H, Tanaka T. Bonding fixed 
prosthodontic composite resin and precious metal alloys with the use of a vinyl-thiol primer and an adhesive opaque resin. J Prosthet Dent 1992; 67: 296-300.

40) Yoshida K, Atsuta M. Effect of MMA-PMMA resin polymerization initiators on the bond strengths of adhesive primers for noble metal. Dent Mater 1999; 15: 332-336.

41) Kadoma Y, Kojima K, Tamaki Y, Nomura Y. Water durability of resin bond to pure gold treated with various adhesion promoting thiirane monomers. Dent Mater J 2007; 26: 29-37.

42) Tanaka T, Atsuta M, Nakabayashi N, Masuhara E. Surface treatment of gold alloys for adhesion. J Prosthet Dent 1988; 60: $271-279$
43) Kajihara H, Suzuki S, Kurashige H, Minesaki Y, Tanaka T. Bonding abutments to cast metal post/cores: comparison of pre-treatment effects. J Oral Rehabil 2003; 30: 119-124.

44) Abreu A, Loza MA, Elias A, Mukhopadhyay S, Looney S, Rueggeberg FA. Tensile bond strength of an adhesive resin cement to different alloys having various surface treatments. J Prosthet Dent 2009; 101: 107-118.

45) Hansson O, Bergström B. A longitudinal study of resin-bonded prostheses. J Prosthet Dent 1996; 76: 132-139.

46) Hikage S, Hirose Y, Sawada N, Endo K, Ohno H. Clinical longevity of resin-bonded bridges bonded using a vinyl-thiol primer. J Oral Rehabil 2003; 30: 1022-1029. 